\title{
Brigada Sanitaria Adriana Haidar: solidaridad técnica montonera con la revolución sandinista
}

\author{
Adriana Haidar Health Brigade: \\ Montonera Technical Solidarity \\ with the Sandinista Revolution
}

\author{
Eudald Cortina Orero \\ (1) https://orcid.org/0000-0002-1405-8188 \\ Grupo de Investigación de Historia de América \\ Universidad de Santiago de Compostela, España \\ eudald.cortina@usc.es
}

Resumen: La revolución sandinista recibió la solidaridad de diferentes contingentes internacionalistas que apoyaron el esfuerzo insurreccional del Frente Sandinista de Liberación Nacional (FSLN) y participaron de la consolidación del proyecto revolucionario y la reconstrucción de Nicaragua. Este artículo estudia el caso inédito de la Brigada Sanitaria Adriana Haidar, estructura conformada en México por el Movimiento Peronista Montonero (МРм). Abordamos esta experiencia centrándonos en cuatro aspectos. Rastreamos, primero, las redes transnacionales generadas por Montoneros entre 1974 y 1979. Identificamos, en segundo lugar, los aportes efectivos del contingente $y$ las proyecciones solidarias de esta experiencia. En tercer lugar, analizamos el impacto en términos personales y militantes sobre los integrantes de la Brigada. Y, finalmente, enmarcamos estas experiencias internacionalistas en las dinámicas organizativa de Montoneros en este periodo, marcadas por la llama-

Cómo cITAR: Cortina Orero, E. (2020). Brigada Sanitaria Adriana Haidar: solidaridad técnica montonera con la revolución sandinista. Secuencia (108), e1832. DoI: https://doi.org/10.18234/secuencia.v0i108.1832

cc $(1)$ Esta obra está protegida bajo una Licencia Creative Commons Atribución-NoComercial 4.0 Internacional. 
da Contraofensiva Estratégica, que tuvo como objetivo el retorno escalonado de militantes montoneros a Argentina para combatir a la dictadura militar.

Palabras clave: militancias transnacionales; internacionalismo; revolución sandinista; montoneros; solidaridad.

Abstract: The sandinista revolution received the solidarity of various internationalist contingents that supported the insurrectionary effort of the Sandinista National Liberation Front (FSLN) and participated in the consolidation of the revolutionary project and the reconstruction of Nicaragua. This article studies the unprecedented case of the Adriana Haidar Health Brigade, a structure created in Mexico by the Montonero Peronist Movement (MPM). We explore this experience by focusing on four aspects. First, we trace the transnational networks created by Montoneros between 1974 and 1979. Second, we identify the effective contributions of the contingent, and the solidarity projections of this experience. Third, we analyze the impact in personal and militant terms on members of the Brigade. And lastly, we frame these internationalist experiences within the organizational dynamics of Montoneros in this period, marked by the so-called Strategic Counteroffensive, designed to achieve the phased return of Montonero militants to Argentina to combat the military dictatorship.

Palabras clave: transnational militancies; internationalism; sandinista revolution; montoneros; solidarity.

Recibido: 29 de febrero de 2020 Aceptado: 3 de julio de 2020

Publicado: 22 de diciembre de 2020

\section{UNA MIRADA TRANSNACIONAL PARA EL ESTUDIO DE LA MOVILIZACIÓN REVOLUCIONARIA}

a investigación en torno a la movilización revolucionaria en América La-
tina se ha caracterizado por un enfoque eminentemente nacional, centra-
do en análisis sobre movimientos específicos y casos nacionales. Los trabajos 
con una perspectiva regional son escasos y en buena medida han tendido, como señala Rey Tristán (2014), a la recopilación de estudios de caso. Una tendencia que es común tanto en América Latina como en Europa y que, con excepciones, sigue siendo la norma en las recientes publicaciones sobre este fenómeno (Ríos y Azcona, 2019).

Sin embargo, diversos enfoques que incorporan la dimensión regional y transnacional al estudio de la movilización revolucionaria latinoamericana se han abierto paso recientemente. En este ámbito destacan tres propuestas: 1) la perspectiva regional de largo plazo planteada por Marchesi (2019) para el estudio de las organizaciones revolucionarias del Cono Sur; 2) los estudios sobre militancias transnacionales que han puesto el foco en la interacción entre militantes y organizaciones revolucionarias de diversos países latinoamericanos (Harmer y Martín Álvarez, 2017); y 3) el análisis impulsado por el propio Martín Álvarez y Rey Tristán (2018), quienes insertan los procesos revolucionarios en América Latina en un ciclo de movilización a escala global que, siguiendo la propuesta de Rapoport (2004 y 2017), identifican como de Nueva Izquierda.

Esta producción ha permitido abordar estos procesos no como experiencias aisladas, sino como parte de una oleada de movilización durante la cual las organizaciones revolucionarias latinoamericanas compartieron marcos interpretativos, estrategias de movilización y se dotaron de un ethos revolucionario común. Partiendo de esta evidencia y retomando el enfoque transnacional, Martín Álvarez y Rey Tristán (2012 y 2017) identifican como uno de los grandes retos para la investigación en torno a la movilización revolucionaria de la oleada el análisis de los procesos de difusión transnacional de ideas y los vínculos formales e informales generados entre las organizaciones revolucionarias de diversos países a lo largo del ciclo revolucionario.

Desde otra perspectiva, autores como Roniger (2012) y Yankelevich (2016) han defendido la necesidad de profundizar en el estudio de los exilios latinoamericanos de la segunda mitad del siglo xx, incorporando a la investigación sobre este fenómeno aspectos menos abordados como el activismo político en el extranjero, las relaciones entre exiliados de diversos países y la conformación de redes de apoyo y solidaridad. El vacío en torno a estos aspectos es, además, particularmente significativo en el estudio de las organizaciones político-militares.

Retomando estas propuestas teóricas, este artículo tiene como objetivo abordar la experiencia internacionalista en Nicaragua de la organización 
Montoneros y, en particular, la conformación de la Brigada Sanitaria Adriana Haidar impulsada desde México por la Rama de Intelectuales y Profesionales del Movimiento Peronista Montonero (MPM). Reconstruiremos esta experiencia enfocándonos en cuatro aspectos. En primer lugar, buscamos identificar las redes que permitieron la incorporación de militantes montoneros al proceso sandinista. En segundo lugar, analizaremos los aportes y la participación efectiva de este contingente internacionalista en la etapa insurreccional y las proyecciones solidarias de esta experiencia en la organización de nuevos equipos técnicos y sanitarios en apoyo a la Nicaragua sandinista. En tercer lugar, rastrearemos el impacto en términos personales y militantes que esta experiencia internacionalista tuvo sobre los integrantes de la Brigada Sanitaria. Y, finalmente, abordaremos la conformación de los contingentes internacionalistas montoneros en el contexto de las dinámicas internas de la organización que la impulsó. En este sentido, analizaremos las proyecciones internacionalistas de Montoneros en Nicaragua en el marco de la llamada Campaña de Contraofensiva Estratégica, impulsada por esta organización desde 1979, y que tuvo como objetivo el retorno escalonado de militantes montoneros a Argentina para combatir a la dictadura militar.

Las dinámicas transnacionales de Montoneros y sus experiencias internacionalistas en Centroamérica han sido, hasta el momento, escasamente abordadas. En este ámbito hemos aportado dos trabajos. En el primero de ellos, analizamos el impacto de la revolución sandinista en términos de proyecciones orgánicas, estrategias de movilización y redefiniciones ideológicas sobre los colectivos procedentes del Partido Revolucionario de los Trabajadores -Ejército Revolucionario del Pueblo (PRT-ERP) y Montoneros (Cortina Orero, 2017)-. En el segundo, abordamos las transformaciones experimentadas en el imaginario antiimperialista montonero desde 1976, a raíz del exilio de sus militantes y su Conducción Nacional, con el efecto que este hecho tendría en términos de colaboración transnacional en el ámbito de denuncia y solidaridad y la concreción de nuevos vínculos organizativos de carácter internacional tanto en América Latina como en Europa y Oriente Medio (Cortina Orero, 2020).

Otro aspecto de la actividad transnacional de Montoneros que ha recibido interés es la conformación, en Costa Rica, de Radio Noticias del Continente, emisora que sería clave en el establecimiento de relaciones con el Frente Sandinista de Liberación Nacional (FSLN) y las organizaciones revolucionarias salvadoreñas (García Fernández, 2018; Rodríguez Esperón, 2018). Desde el campo de la memoria, encontramos en este ámbito el relato de Raúl 
Cuestas (2005), director de RNC, y la biografía del dirigente montonero Fernando Vaca Narvaja (Vaca Narvaja y Frugoni, 2002), responsable de los contingentes montoneros en Nicaragua.

En relación con las fuentes utilizadas para este artículo, partimos de una base de fuentes orales en función de entrevistas realizadas en Argentina, México y Nicaragua a integrantes de la Brigada Sanitaria Adriana Haidar, a miembros del contingente militar de Montoneros en Nicaragua y exiliados del espacio montonero en México. En cuanto a las fuentes documentales empleadas, utilizamos el archivo documental de la propia Brigada Sanitaria, fuentes hemerográficas y documentales de Montoneros y de sus escisiones en el periodo, procedentes del Centro de Documentación de los Movimientos Armados (CEDEma) y, por último, el Fondo Equipo Internacionalista México-Nicaragua, depositado en el Archivo Histórico de la UNAM.

\section{DE TORRIJOS AL FSLN: MILITANCIAS TRANSNACIONALES Y REDES SOLIDARIAS EN EL EXILIO}

A inicios de 1979, una delegación del FSLN integrada por los hermanos Daniel y Humberto Ortega se reunieron, en una finca costarricense, con el miembro de la Conducción Nacional de Montoneros y responsable de su Secretaría de Relaciones Exteriores (SRE), Fernando Vaca Narvaja (Vaca Narvaja y Frugoni, 2002). Este encuentro culminaría los acercamientos que, en distintos niveles, se fueron dando desde 1975 entre el FSLN y Montoneros, y sellaría la formación de los dos contingentes montoneros que se integraron al proceso sandinista: la Brigada Sanitaria Adriana Haidar y el Grupo de Combate General San Martín.

La relación de Montoneros con las organizaciones revolucionarias y los procesos de transformación en Centroamérica se acentuaron con la instauración de la dictadura militar en Argentina, en marzo de 1976, y la salida al exilio de sus militantes y de su conducción política. Sin embargo, es necesario identificar una serie de vínculos previos que, una vez asentados en el exterior, permitieron el establecimiento de redes solidarias, la conformación de representaciones políticas en países como México, Panamá y Costa Rica, además de la concreción de coordinaciones de carácter conspirativo.

En abril de 1974, una delegación de Montoneros y de sus organismos de superficie inició en Panamá una gira internacional que incluyó visitas a Méxi- 
co, Cuba y Perú. ${ }^{1}$ La gira fue resultado de la invitación efectuada a la Juventud Peronista (JP) por el presidente panameño Omar Torrijos, durante su visita a Argentina en enero de ese mismo año. ${ }^{2}$ Para entonces, Montoneros establecía un paralelismo entre el torrijismo y el movimiento peronista, identificando a Torrijos y Panamá como uno de los principales baluartes antiimperialistas en América Latina, junto a Cuba, Perú y la propia Argentina. ${ }^{3}$

En Panamá, la visita montonera adquirió carácter oficial, siendo recibida por el mayor Roberto Díaz, en representación del Estado Mayor. Durante su estancia en el país, la delegación montonera se reunió nuevamente con el general Torrijos y estableció relaciones con organizaciones sociales panameñas como la Federación de Estudiantes Panameños, la Central Nacional de Trabajadores y la Federación de Mujeres de Panamá. ${ }^{4}$ En el informe presentado a su retorno, la representación de la JP señaló como principales objetivos de su visita el "establecimientos de nuevos vínculos" y el inicio de "una coordinación político-organizativa" con grupos juveniles antiimperialistas y revolucionarios. ${ }^{5}$

Bajo esta misma lógica, un grupo reducido de la delegación viajó a México donde permaneció una semana, prosiguiendo la gira con visitas a Cuba y Perú. En México, los delegados de JP, JTP y JUP se reunieron con organizaciones juveniles vinculadas al Partido Revolucionario Institucional (PRI), como el Movimiento Nacional Juvenil Revolucionario (MNJR), la Confederación de Jóvenes Mexicanos y la juventud del Partido Popular Socialista (PPs). La visita adquirió mayor rango institucional, a raíz de la reunión que la delegación

${ }^{1}$ En la gira internacional participaron una treintena de representantes de la Juventud Peronista (JP), Juventud Trabajadora Peronista (JTP), Juventud Universitaria Peronista (JUP), Unión de Estudiantes Secundarios (UEs), Movimiento Villero Peronista (MVP) y la Agrupación Evita.

2 "Torrijos: Un General Peronista", El Descamisado, núm. 36, pp. 6-7. Ref. B-3. Fondos del Centro de Documentación de los Movimientos Armados (en adelante Cedema), Valencia, España.

3 “Panamá contra el imperio", El Descamisado, núm. 36, 22 de enero de 1974, p. 8. Ref. B-3. Cedema, Valencia, España.

4 "Montoneros con el pueblo panameño", El Peronista, núm. 2, 26 de abril de 1974, pp. 19-23; "Guardia Nacional: un ejército que quiere a su patria", El Peronista, núm. 2, 26 de abril de 1974, pp. 26-32. Ref. B-6. CedEMA, Valencia, España.

5 "A la vuelta", El Peronista, núm. 2, 26 de abril de 1974, pp. 24-25. Ref. B-6. Cedema, Valencia, España. 
sostuvo con el presidente mexicano, Luis Echeverría, quien recibió en la residencia presidencial de Los Pinos a los militantes argentinos. ${ }^{6}$

La relación entre el peronismo montonero y Echeverría se consolidó en los siguientes años de la mano del exrector de la Universidad de Buenos Aires, Rodolfo Puiggrós. Las acciones de la Alianza Anticomunista Argentina (AAA) habían empujado al exilio a referentes del peronismo revolucionario y destacados intelectuales durante el mandato de María Estela Martínez de Perón. Para Puiggrós era su segundo exilio en México, país en el que había residido entre 1961 y 1967, ejerciendo como profesor de la Universidad Nacional Autónoma de México (UNAM) y participando en la fundación del periódico El Día. El prestigio académico de Puiggrós, su ascendencia sobre las instituciones mexicanas y sus lazos de amistad con personalidades de los variados exilios latinoamericanos en México, lo convertirían en una figura clave para la construcción de las redes de Montoneros en este país y de cara a Centroamérica.

Siguiendo el testimonio de José Miguel Candia, sociólogo argentino exiliado en México y colaborador directo de Puiggrós, el profesor asentó sus relaciones con el PRI y el Estado mexicano en función de su cercanía con dos figuras: la del político, jurista e ideólogo del PRI, Jesús Reyes Heroles, y la del propio presidente Echeverría. En este sentido, el espacio montonero logró articular canales de comunicación directos con Presidencia y la Secretaría de Gobernación. "No era fácil hablar con el Estado mexicano. No era cualquier Estado. Ni Pinochet ni Fidel Castro. Era otro ente. Así las cosas, gente como Rodolfo [Puiggrós], también Don Ricardo [Obregón Cano], ${ }^{7}$ reconocido y con espacio para platicar y resolver broncas también. Rodolfo era un tipo muy reconocido intelectualmente, tenía vasos comunicantes. Sí, era uno de los fusibles con el Estado."8

El exrector de la UBA sería igualmente clave en la articulación de redes de exiliados. En 1975 se conformó en México el Comité de Solidaridad Latinoamericana, que agrupó a los referentes intelectuales y políticos latinoamericanos asentados en este país. Puiggrós ocupó la representación argentina (Yankelevich, 2010), en un organismo en el que participaron personalidades

6 "Así también se camina hacia la patria grande", El Peronista, núm. 4, 14 de mayo de 1974, pp. 20-22. Ref. B-6. Cedema, Valencia, España.

${ }^{7}$ Exgobernador de la provincia de Córdoba, adherente al peronismo revolucionario, exiliado en México desde 1974.

${ }^{8}$ Entrevista a José Miguel Candia, realizada por Eudald Cortina Orero, el 30 de enero de 2018. Ciudad de México, México. 
como el brasileño Francisco Julião, el chileno Pedro Vuskovic, el uruguayo Carlos Quijano o Gerard Pierre-Charles, en representación del exilio haitiano.

La oposición nicaragüense estuvo representada por el poeta Francisco de Asís Fernández, quien un año antes había fundado el Comité Mexicano de Solidaridad con el Pueblo de Nicaragua (CMSPN), y con quien Puiggrós estableció una relación de amistad. ${ }^{9}$ Este vínculo alentó los primeros contactos indirectos y las expresiones de apoyo de Montoneros hacia la lucha del FSLN, en un momento en que la actividad política montonera se inscribía todavía en una lógica eminentemente nacional. Así, entre el 24 de noviembre y el 5 de diciembre de 1975, México acogió la Segunda Jornada de Solidaridad con el Pueblo de Nicaragua. Puiggrós ejerció como uno de los principales oradores del encuentro, que contó con la adhesión de Montoneros y el Movimiento Peronista Auténtico, organismo electoral promovido por la organización clandestina. ${ }^{10}$

El exilio argentino en México, agrupado en la Comisión Argentina de Solidaridad (CAs), se dividió a finales de 1975 al constituirse el Comité de Solidaridad con el Pueblo Argentino -inicialmente, Comité de Solidaridad con el Pueblo Argentino en Lucha por su Liberación-. El cospa se lanzó públicamente en diciembre de 1975 coincidiendo con la Segunda Jornada de Solidaridad con el Pueblo de Nicaragua, en una nota de adhesión firmada por Carlos Suárez y Rodolfo Puiggrós. ${ }^{11}$ Ambos integrarían con posterioridad el Consejo Superior del Movimiento Peronista Montonero (MPM). El cospa se vería reforzado con la masiva llegada de exiliados argentinos que siguió al golpe de Estado de marzo de 1976 y el respaldo del gobierno mexicano. Si bien inicialmente aglutinó a otras expresiones vinculadas a la izquierda armada argentina, el cosPA sería rápidamente cooptado por Montoneros, convirtiéndose en una plataforma para las relaciones internacionales de esta organización (Yankelevich, 2010; Rojas Mira, 2014).

cospa, primero, y la Casa Montonera, después, se convirtieron en ámbitos de sociabilidad para el exilio montonero en México, pero también en es-

${ }^{9}$ José Miguel Candia, entrevista citada.

${ }^{10}$ Movimiento Peronista Auténtico (1 de diciembre de 1975). El año 2000 nos encontrará unidos o dominados; Montoneros (1 de diciembre de 1975). A los compañeros organizadores del acto de solidaridad con el pueblo nicaragüense. Gaceta Sandinista, 6/7, Suplemento Jornada de Solidaridad con el Pueblo de Nicaragua (1976), pp. VI-VII. Ref. A-41. Cedema, Valencia, España.

${ }^{11}$ Carlos Suárez (secretario de Prensa) y Rodolfo Puiggrós (secretario de Relaciones (1 de diciembre de 1975). Compañeros del Comité Mexicano de Solidaridad con el Pueblo de Nicaragua. Gaceta Sandinista, 6/7, Suplemento Jornada de Solidaridad con el Pueblo de Nicaragua (1976), p. viII. Ref. A-41. CedemA, Valencia, España. 
pacios que permitieron el vínculo informal con otros militantes latinoamericanos. Al respecto, los militantes montoneros identifican la Casa Argentina como el ámbito en el que pudieron conocer de primera mano los procesos revolucionarios centroamericanos, a raíz de la organización de peñas, campeonatos deportivos y actividades solidarias con participación de colectivos nicaragüenses, salvadoreños y guatemaltecos. Pero también, como un espacio concreto de solidaridad montonera hacia los militantes centroamericanos, expresado en la atención psicológica a activistas refugiados en México y la integración de sus hijos a la Casa del Niño, dirigida por Graciela Gómez (Cortina Orero, 2020).

La escalada represiva que siguió a la instauración de la dictadura militar en Argentina determinó el repliegue al exterior de la Conducción Nacional de Montoneros. La organización debió acomodarse a una nueva etapa marcada por el predominio de la actividad política fuera del territorio argentino, impulsando organismos de solidaridad allí donde se asentó su militancia, y dotándose de una nueva estructura organizativa acorde a las necesidades marcadas por la actividad transnacional. En esta línea, en abril de 1977 se lanzó públicamente el Movimiento Peronista Montonero (MPM). Este cumpliría una doble función. Por un lado, permitía reagrupar a un conjunto de activos que, si bien habían cesado su militancia en la organización, seguían asumiéndose partícipes del espacio montonero. Por otro lado, se constituía como un organismo amplio y de naturaleza pública capaz de vincularse con instituciones internacionales, gobiernos y organizaciones políticas de naturaleza diversa.

Con esta lógica, el MPM impulsó una Secretaría de Relaciones Exteriores (SRE) encargada de desarrollar las actividades de solidaridad, visibilizar a la organización en los foros internacionales y establecer vínculos con otros movimientos revolucionarios. ${ }^{12}$ En este ámbito, la labor del MPM se completaría con el establecimiento de representaciones y delegados internacionales y el impulso de medios de difusión. Entre estos destacaron la revista Vencer, órgano impreso internacional del MPM, y la emisora de onda corta asentada en Costa Rica "TIRL Radio Noticias del Continente" (RNC). La radio comenzó sus transmisiones de prueba a finales de 1978, como un esfuerzo comunicativo que pretendía romper, desde el exterior, la censura implantada por la dictadura argentina. Sin embargo, pronto trascendería el ámbito argentino para convertirse en un instrumento de difusión de las luchas revolucionarias

${ }_{12}$ Movimiento Peronista Montonero. Resistir es vencer. Roma, abril de 1977. Ref. A-29. Cedema, Valencia, España. 
en América Latina y, particularmente, en Centroamérica (García Fernández, 2018; Rodríguez Esperón, 2018).

Radio Noticias del Continente cumplió una función propagandística y de difusión a la vez que actuaba como una herramienta que permitió el establecimiento de redes conspirativas entre militantes argentinos y las estructuras sandinistas que operaban en Costa Rica. En este sentido, y siguiendo el testimonio de Raúl Cuestas (2005), RNC sirvió como enlace en la incorporación de internacionalistas argentinos que, de forma inorgánica, se sumaron a la Revolución Sandinista, como José Sbezzi, desde Suecia, y de Carlos Balerini y José Ramón Morales, quienes lo acompañarían desde el exilio mexicano. La emisora facilitaría igualmente el establecimiento de vínculos directos entre el FSLN y Montoneros. ${ }^{13}$

Si en el ámbito de la solidaridad, la estrategia de Montoneros se caracterizó por una política amplia en la vinculación con las diversas fuerzas de oposición al somocismo, en el terreno conspirativo la organización argentina estrecharía sus alianzas con la tendencia insurreccional o tercerista del FSLN. En este vínculo pesaría la propia estrategia internacional de los terceristas, capaz de atraer el apoyo de la socialdemocracia europea como del Departamento América cubano, así como cierta sintonía ideológica entre las dos organizaciones latinoamericanas. Para Montoneros, esta afinidad partía, precisamente, del no alineamiento de la tendencia insurreccional y de la importancia de los referentes nacionales y la historia nicaragüense en la ideología y estrategia política del FSLN. ${ }^{14}$ En este punto, Montoneros percibía al sandinismo como un movimiento nacional que, al igual que el peronismo en Argentina, se nutría de la alianza de distintas fuerzas sociales enfrentadas al imperialismo. ${ }^{15}$

En un contexto caracterizado por la lucha antidictatorial en Argentina y Nicaragua, a mediados de 1977 se produjo el primer contacto entre el FSLN y Montoneros, en una reunión en la que los representantes de la tendencia insurreccional del fSLN, Plutarco Hernández Sancho y Humberto Ortega,

${ }^{13}$ Morales moriría en el Frente Sur en enero de 1979, ya incorporado a las filas del FSLN. Sbezzi y Balerini proseguirían su actividad internacionalista en las filas de la Resistencia Nacional (RN) salvadoreña al triunfo de la Revolución Sandinista. El primero sería detenido en Costa Rica, junto a otros militantes de la RN, en 1983, mientras que Balerini sería secuestrado y desaparecido por organismos de inteligencia en Honduras en agosto de 1981.

14 "Editorial", Evita Montonera, núm. 25, agosto de 1979, pp. 3-6. Ref. A-12; "Nicaragua liberada”, Vencer, núms. 2-3, 1979, pp. 33-35. Ref. A-9. CedemA, Valencia, España.

${ }^{15}$ Las dictaduras no caen, se derriban. Entrevista con el profesor Puiggrós. Vencer, núm. 4, 1980, pp. 10-11. Ref. A-9. Cedema, Valencia, España. 
plantearon el establecimiento de relaciones orgánicas y solicitaron instructores militares para los campamentos del fSLN en Costa Rica (Cuestas, 2005). Una versión diferente ofrece el testimonio de Celedonio Carrizo, quien posteriormente integraría el Grupo de Combate General San Martín. Carrizo afirma que entre finales de 1978 e inicios de 1979, siendo un referente visible del MPM en Panamá, fue contactado por una de las estructuras sandinistas en este país, que solicitó ayuda urgente a Montoneros ante una situación de desabastecimiento. ${ }^{16}$ De este contacto inicial, habría derivado la reunión entre los hermanos Ortega y Fernando Vaca Narvaja en Costa Rica.

Estas versiones, lejos de ser excluyentes, evidencian el contacto que, en diferentes niveles, tanto en el ámbito abierto de la solidaridad como con carácter conspirativo, se produjeron entre Montoneros y el Frente Sandinista. Hay que apuntar, además, que desde 1978 la Conducción Nacional de Montoneros buscaría refugio en Cuba a raíz del fracaso de la Operación México, que tuvo como objetivo el secuestro de la dirigencia montonera por agentes de la dictadura argentina (Confino, 2018). Consideramos probable entonces que las dos organizaciones hayan mantenido contactos también en Cuba, país en el que tanto el FSLN como Montoneros contaron con representaciones propias.

Los acercamientos entre Montoneros y FSLN tuvieron como resultado el apoyo técnico, humano y financiero de la organización argentina a la ofensiva insurreccional sandinista. Este respaldo se concretó, como señalamos, en la organización de la Brigada Sanitaria y el Grupo de Combate General San Martín pero, también, en la puesta a disposición del FSLN de la señal de Radio Noticias del Continente, que permitiría respaldar la escasa potencia de la que gozaba la emisora clandestina Radio Sandino (Rodríguez Esperón, 2018).

\section{DE LA INSURRECCIÓN A LA RECONSTRUCCIÓN: LA BRIGADA SANITARIA ADRIANA HAIDAR}

La madrugada del 18 de julio de 1979, un día antes del triunfo definitivo de las fuerzas sandinistas, dos avionetas procedentes de San José (Costa Rica) descendieron sobre suelo nicaragüense en el departamento de Carazo, territorio del Frente Sur-Oriental "Camilo Ortega", para entonces, zona ya liberada por

${ }^{16}$ Entrevista a Celedonio Carrizo, realizada por Eudald Cortina Orero, el 31 de agosto de 2016. Buenos Aires, Argentina. 
el FSLN. ${ }^{17} \mathrm{El}$ grupo estaba conformado inicialmente por nueve integrantes. Cuatro médicos (el cirujano Ricardo Yofre, el psiquiatra infantil Juan Carlos Volnovich, la psicóloga y sanitarista Alicia Gillone y la psiquiatra Sylvia Bermann, quien asumiría la dirección de la Brigada); el odontólogo Luciano de Gatica; y dos enfermeras (Mercedes Inés Moya, enfermera pediátrica, y Patricia Vaca Narvaja, instrumentista). ${ }^{18}$ Completarían el equipo técnico el bioquímico Ricardo Holland y el economista Luis Castillo, que actuaría como administrador del grupo.

Con la excepción de Volnovich, todos los integrantes de la Brigada Sanitaria procedían del exilio mexicano y estaban vinculados a la Rama de Intelectuales y Profesionales del Movimiento Peronista Montonero (MРм). Atendiendo a los informes económicos de la Brigada, el grueso de su financiación procedió del propio MPM y, en menor medida, de aportes personales y del cospa.

La organización de la Brigada es un ejemplo de las complejas redes generadas por Montoneros en el exilio. Si bien su concreción partió del acuerdo entre dos estructuras revolucionarias clandestinas, Montoneros y FSLN, su organización precisó del apoyo directo e indirecto de los gobiernos de México y Cuba, y se nutrió de la infraestructura generada en Costa Rica por Montoneros, a través de Radio Noticias del Continente.

En México, atendiendo a las excelentes relaciones que mantenía Puiggrós, el grupo contó con el aval de la Secretaría de Gobernación lo que permitió regularizar la salida del contingente, así como de los insumos sanitarios que acompañaron al grupo. Los integrantes de la brigada, algunos de los cuales ejercían su actividad profesional en la UNAM y en la Universidad Autónoma Metropolitana (UAM), contaron con licencia en sus respectivos trabajos. ${ }^{19}$ Entre su convocatoria y la salida de México no pasaron más de dos semanas. La coordinación recayó en Ricardo Yofre y Luis Castillo. ${ }^{20}$ Además del acopio de insumos, el grupo buscó informarse de las condiciones en las que se desa-

${ }^{17}$ Brigada Sanitaria "Adriana Haidar". Informe de actividades realizadas durante su primera semana de estadía en la ciudad de Diriamba. Diriamba, 24 de julio de 1977. Ref. DigAPLg. Cedema, Valencia, España.

${ }^{18}$ Patricia Vaca Narvaja fue embajadora argentina en México, entre 2010 y 2015, durante la presidencia de Cristina Fernández de Kirchner.

${ }^{19}$ Entrevista a José Carlos Escudero, realizada por Eudald Cortina Orero, el 12 de diciembre de 2016. Ciudad Autónoma de Buenos Aires, Argentina.

${ }^{20}$ Entrevista a Luciano de Gatica, realizada por Eudald Cortina Orero, 21 de septiembre de 2016. Luján, provincia de Buenos Aires, Argentina. 
rrollaría su actividad en Nicaragua. En este punto, la dirección de la Brigada lamentó, a su retorno, la descoordinación con los representantes del FSLN en México, que no estaban informados de su integración al proceso, lo que les impidió contar con "valiosa información" que sí recibieron otros contingentes. ${ }^{21}$

Desde Cuba debían sumarse al contingente dos médicos argentinos residentes en este país: Leonardo Werthein y su cuñado Juan Carlos Volnovich. Werthein había participado como médico en el foco guerrillero del Ejército Guerrillero del Pueblo (EGP), impulsado por Jorge Ricardo Masetti en Salta, Argentina, entre 1963 y 1964, y era un militante con ascendencia familiar dentro del Departamento América del Partido Comunista Cubano (PCC). Sin embargo, su doble nacionalidad (argentina y cubana) determinaron su no incorporación al grupo, pues se asumía que la presencia cubana en apoyo del FSLN podía ser utilizada como pretexto, por parte de Estados Unidos, para intervenir directamente en Nicaragua. Volnovich, en cambio, sería invitado por el Departamento América a sumarse a la brigada que se estaba conformando en México. Así, viajó a este país, donde sería recibido por un militar cubano:

Cuando llegué yo, me dice el hombre: "Mucho gusto. ¿Y usted qué hace?"

-Yo soy psicoanalista.

Creo que era la primera vez en la vida que escuchaba la palabra psicoanalista. Cuando yo vi que el abrió los ojos como dos huevos duros, entonces me di cuenta de que tenía que aclararle algo más y le dije: "Soy psicoanalista de niños”. A lo cual el hombre se quedó totalmente perplejo, sin decirme una palabra, se levantó y se fue. Me dejo ahí. Seguramente se debe haber ido a consultar algo. Volvió y me dijo: "Pero dígame una cosa, ¿usted es médico?"

-Sí, soy médico.

-Ah, bueno, porque necesitamos un anestesista para un quirófano en el frente de batalla.

-Pero yo no soy anestesista...

-Pero eso se puede arreglar. ${ }^{22}$

${ }^{21}$ Brigada Sanitaria "Adriana Haidar". Informe para el Consejo Superior del Movimiento Peronista Montonero sobre la actuación de la Brigada Sanitaria Adriana Haidar. Diciembre de 1979. Ref. Dig-APLg. Cedema, Valencia, España.

${ }^{22}$ Entrevista a Juan Carlos Volnovich, realizada por Eudald Cortina Orero, el 15 de septiembre de 2016. Ciudad Autónoma de Buenos Aires, Argentina. 
Al igual que Volnovich, Sylvia Bermann, también psiquiatra, recibiría formación como anestesista, actividad que nunca llegaría a desarrollar como brigadista. ${ }^{23}$ Estos testimonios dan cuenta no sólo del entramado de redes transnacionales que acompañaron esta experiencia internacionalista, sino que muestran, también, los objetivos iniciales de la Brigada, formada "para hacer sanidad de guerra" en apoyo de la insurrección, en las filas del FSLN. ${ }^{24}$ Bajo esta lógica, el grupo partiría de México a Costa Rica, entre mayo y junio de 1979, asentándose hasta su traslado definitivo a Nicaragua en las instalaciones de Radio Noticias del Continente. Durante su estancia en Costa Rica, el grupo se reunió con miembros de la Conducción Nacional de Montoneros y recibió la visita de los dirigentes sandinistas Víctor Tirado López y Humberto Ortega.$^{25}$

El ingreso del contingente se retrasó hasta el 18 de julio al demorarse las medicinas y el equipamiento sanitario pensado para la atención de cien pacientes. No obstante, la limitada capacidad de las avionetas con las que entró el contingente obligó a dejar en Costa Rica buena parte de los insumos: "Descendemos cerca de la ciudad de Diriamba, pero en una ruta [carretera]. Estaba amaneciendo y aparentemente estaba desierto, pero cuando para el avión, no terminamos de abrir la puerta, un enjambre de hormigas sandinistas para vaciar todo y llevar la medicación y a nosotros a un lugar seguro."26

Tras entablar contacto con las autoridades del FSLN en Diriamba, se plantearon tres espacios para que se asentara el contingente sanitario: Diriamba, el hospital de Jinotepe y el de Masaya. Este último fue descartado por las condiciones de guerra, mientras el de Jinotepe se encontraba sobrepasado en su capacidad asistencial y demandaba más insumos que personal técnico. Finalmente, se optó por el asentamiento del grupo en el hospital San José de Diriamba, dependiente de las monjas josefinas. El hospital se encontraba

${ }^{23}$ Sylvia Bermann, al C. Mario Eduardo Firmenich, secretario general, Movimiento Peronista Montonero. México, 7 de diciembre de 1979. Ref. Dig- APLg. Cedema, Valencia, España.

${ }^{24}$ Brigada Sanitaria "Adriana Haidar". Informe a Patricia Quintana, coordinadora en el Área de Salud de Diriamba, y Raúl Estrada, miembro de la Junta de Gobierno y Responsable de Área de Salud. Diriamba, septiembre de 1979. Ref. Dig- APLg. Cedema, Valencia, España.

${ }^{25}$ Brigada Sanitaria "Adriana Haidar". Informe para el Consejo Superior del Movimiento Peronista Montonero sobre la actuación de la Brigada Sanitaria Adriana Haidar. Diciembre de 1979. Ref. Dig- APLg. Cedema, Valencia, España. Sobre esta reunión, Volnovich recuerda que Humberto Ortega obsequió al grupo con una ametralladora liviana, a la que llamaban "polaquita" por su origen.

${ }^{26}$ Luciano de Gatica, entrevista citada. 
en una situación "precaria" y había sido desmantelado, pero ofrecía ventajas para su reorganización y el desarrollo de un plan sanitario para el municipio.

Desde este momento, la Brigada Sanitaria empezaría a trabajar sobre dos objetivos: desarrollar la actividad asistencial y coordinarse con "los grupos de salud relacionados con el FSLN" y las organizaciones de masas para efectuar un "relevamiento del estado sanitario de la población". ${ }^{27}$ La Brigada, que se había preparado para desarrollar su trabajo en un contexto bélico, había llegado a Nicaragua para "la pirotecnia" final, teniendo que adaptar sus objetivos hacia una lógica de reconstrucción.

Aunque el grueso de la atención médica militar pasó a depender del naciente Ejército Popular Sandinista (EPS), la Brigada Sanitaria siguió prestando asistencia a los heridos por arma de guerra durante la etapa postinsurreccional, así como a los milicianos de la Escuela de Instrucción Militar "Israel Lewites".

En la nueva dinámica de reconstrucción, los esfuerzos de sus integrantes se orientaron a dotar a Diriamba de unas estructuras asistenciales básicas, implementar un plan de salud, poniendo el foco en las acciones preventivas y la educación sanitaria de sus habitantes, y el desarrollo de acciones para la formación y especialización de personal sanitario local. En este sentido, la Brigada puso en marcha un curso de enfermería, que formó durante un mes a una treintena de mujeres con el objetivo de mejorar la labor asistencial, ${ }^{28} \mathrm{e}$ implementó un taller de formación en pediatría para alumnos avanzados de la escuela de medicina. Esta acción fue desarrollada por el pediatra Pedro Sarrasqueta que, junto al sanitarista José Carlos Escudero, se sumaron al grupo durante dos semanas. ${ }^{29}$ La actividad pediátrica, desarrollada por Volnovich, la enfermera Mercedes Inés Moya y el propio Sarrasqueta, concentró buena parte de los esfuerzos de la Brigada, que describía la situación de la infancia en estos términos: "El sector más castigado era el de la población infantil, afectada por cuadros muy severos. Especialmente en sus áreas rurales, la carencia de

${ }^{27}$ Brigada Sanitaria "Adriana Haidar”. Informe de actividades realizadas durante su primera semana de estadía en la ciudad de Diriamba. Diriamba, 24 de julio de 1977. Ref. DigAPlg. Cedema, Valencia, España.

${ }_{28}$ Patricia Vaca Narvaja. Plan de salud. Sector de Enfermería. Diriamba, 24 de julio de 1979. Ref. Dig- APlg. Cedema, Valencia, España.

${ }^{29}$ Brigada Sanitaria “Adriana Haidar". Informe para el Consejo Superior del Movimiento Peronista Montonero sobre la actuación de la Brigada Sanitaria Adriana Haidar. Diciembre de 1979. Ref. Dig- APlg. Cedema, Valencia, España. 
normas de vacunación y de saneamiento ambiental, de vivienda aceptable y, sobre todo, de leche y alimentos suficientes, agravada por la falta de recursos asistenciales era condicionante de una verdadera 'hambre' médica." ${ }^{30}$

Para dar respuesta a esta situación, el grupo desarrolló una red asistencial con la organización de dos dispensarios en el área urbana de Diriamba y otros dos en los sectores rurales de Buenavista y San Gregorio, cuyos vecinos bautizaron al dispensario local con el nombre de "Los Montoneros". Estos consultorios complementaban la asistencia central en el Hospital San José de Diriamba, que empezó a ofrecer consultas diarias en medicina general, cirugía, ginecología, psiquiatría y atención pediátrica.${ }^{31}$ En función del trabajo del bioquímico del grupo, Ricardo Holland, la brigada dotaría a este centro de un laboratorio de análisis clínico del que carecía con anterioridad. ${ }^{32}$

Otra de las acciones de la brigada se orientó a asesorar a la Junta de Gobierno municipal de Diriamba en el área de salud. En primer lugar, mediante la elaboración de un censo local, enfocado inicialmente a conocer las necesidades sanitarias de la población, pero que sería utilizada por las nuevas autoridades para implementar un plan de impuestos municipal, elaborado por el economista de la brigada Luis Castillo. ${ }^{33}$ En segundo lugar, adaptando la organización asistencial local a los organismos surgidos del proceso revolucionario. En este ámbito, el grupo apoyaría la conformación de la llamada "Casa de la Salud", organismo que actuaría como enlace entre la administración local y los Comités de Defensa Sandinista. ${ }^{34}$

Junto a las acciones de apoyo y asistencia sanitaria en el departamento de Carazo, algunos integrantes del contingente montonero pasaron a desarrollar tareas de asesoramiento en la fase organizativa del Ministerio de Salud. En estas labores tuvieron especial participación Alicia Gilloni, responsable del di-

${ }^{30}$ Brigada Sanitaria "Adriana Haidar". Informe de actividades realizadas durante su primera semana de estadía en la ciudad de Diriamba. Diriamba, 24 de julio de 1979. Ref. DigAPLg. Cedema, Valencia, España.

${ }^{31}$ Brigada Sanitaria "Adriana Haidar". Informe de actividades realizadas durante su primera semana de estadía en la ciudad de Diriamba. Diriamba, 24 de julio de 1979. Ref. DigAPLg. Cedema, Valencia, España.

${ }^{32}$ Ricardo Holland. Plan de Salud, sector de Laboratorio. Diriamba, 24 de julio de 1979. Ref. Dig- APlg. Cedema, Valencia, España.

${ }^{33}$ Luis Castillo. Plan de Salud, sector de Administración. Diriamba, 24 de julio de 1979. Ref. Dig- APLg. Cedema, Valencia, España.

${ }^{34}$ Brigada Sanitaria "Adriana Haidar". Informe para el Consejo Superior del Movimiento Peronista Montonero sobre la actuación de la Brigada Sanitaria Adriana Haidar. Diciembre de 1979. Ref. Dig- APLg. Cedema, Valencia, España. 
seño del modelo de salud del municipio de Diriamba, el odontólogo Luciano de Gatica, autor del proyecto de asistencia odontológica integral con participación popular, ${ }^{35}$ y el sanitarista José Carlos Escudero. Fruto de esta colaboración Escudero (1980a, 1980b y 1981) elaboró los trabajos "Starting from Year One: The Politics of Health in Nicaragua", publicado en International Journal of Health Services, la monografía "Health Care in the New Nicaragua", editada en Estados Unidos para la campaña solidaria Medical Aid for Nicaragua, y el artículo "Año cero en salud", publicado en México por Cuadernos de Marcha.

Finalmente, atendiendo a la formación de los integrantes de la brigada, se implementaron niveles específicos de atención, en materia odontológica y de atención psiquiátrica. En relación con el primer aspecto, se armó "una red de cobertura asistencial urbana y rural" en el área de Diriamba, ${ }^{36}$ que tuvo continuidad con un proyecto de odontología rural impulsado desde el Instituto Nicaragüense de Reforma Agraria. ${ }^{37}$ Dada la composición del contingente, la asistencia psiquiátrica fue uno de los campos con mayor crecimiento, tanto en adultos como en población infantil, sobrepasando las expectativas iniciales del grupo:

La población afectada tan directamente por los estragos de la guerra concurría en número elevado reclamando alivio a neurosis traumáticas y a estados de pánico ansioso y depresiones que habían aparecido después del triunfo sobre la tiranía, generalmente coincidiendo con duelos de difícil elaboración por la pérdida de seres queridos en el conflicto bélico o por la participación en episodios de extrema tensión y de cercano temor por la pérdida de la vida ante amenazas directas o presencia de torturas y muertes violentas. En ocasiones se trataba de personas que sumaron la terrible experiencia de la guerra a episodios de terror anteriores, como el terremoto del año 1972. La atención a combatientes completó el cuadro de la patología atendida.

${ }^{35}$ Compañero Luciano (de Gatica), MPM, por Comisión Asesora. Proyecto alternativo simplificado, con participación popular, para el Sistema Único de Salud Odontológica Integrado al Sistema Único de Salud. Managua, 4 de julio de 1979 [sic]. Ref. Dig- APLg. Cedema, Valencia, España.

${ }^{36}$ Luciano de Gatica. Plan de Salud, sector de Odontología. Diriamba, 24 de julio de 1979. Ref. Dig- APlg. Cedema, Valencia, España.

${ }^{37}$ Luciano de Gatica, entrevista citada. 
El momento en que la Brigada regresó a tierras mexicanas ofrece algunas dudas. Según el testimonio de Luciano de Gatica, el grupo recibió la orden de volver y salió de Nicaragua en diciembre de 1979, momento en el que está fechado el informe presentado por la dirección de la Brigada Sanitaria a la Conducción Nacional del MPM. Sin embargo, el informe entregado a las autoridades locales como balance de las actividades realizadas por el grupo durante su estancia en Diriamba aparece fechado en septiembre de 1979. Además, María Rosa Renzi, quien comenzó a trabajar para la Junta local de Diriamba en octubre de ese año, afirma que, a su arribo a lo localidad, la estructura sanitaria ya había partido. ${ }^{38}$ En esta línea, consideramos más factible que el contingente abandonara Diriamba entre septiembre y octubre de 1979, momento en el que los integrantes de la Brigada regresaron a México. En algunos casos, como el de Holland, De Gatica o la propia Sylvia Bermann, sería un viaje de ida y vuelta.

\section{CONTRAOFENSIVA, NUEVAS MILITANCIAS Y DISPERSIÓN ORGÁNICA}

La participación internacionalista de la Brigada Sanitaria Adriana Haidar en Nicaragua estuvo atravesada por dos procesos que definieron el carácter de esta experiencia: la situación de exilio de sus componentes y las convulsas dinámicas internas en Montoneros. Desde finales de 1978, la organización revolucionaria argentina inició la preparación y el reclutamiento de militantes para la llamada Contraofensiva Estratégica. Este proyecto contemplaba el ingreso a la Argentina de núcleos militantes especializados para desarrollar acciones de propaganda, sabotaje y ataques directos contra personalidades ligadas al gobierno militar. El retorno al país se efectuó en dos oleadas. La primera, a lo largo de 1979, y la segunda a partir de febrero de 1980 (Confino, 2018).

La incorporación de militantes montoneros al proceso revolucionario sandinista cumplió, además de su carácter internacionalista, una función formativa en la lógica de la Contraofensiva. Este aspecto es generalmente defendido por aquellos militantes que hicieron parte del Grupo de Combate General San Martín, algunos de los cuales reingresaron finalmente a Argenti-

${ }^{38}$ Entrevista a María Rosa Renzi, realizada por Eudald Cortina Orero, el 18 de mayo de 2018. Managua, Nicaragua. 
na (Cortina Orero, 2020). ${ }^{39}$ Menor uniformidad presenta el relato de quienes integraron la Brigada Sanitaria Adriana Haidar, entre los que el componente del retorno en el marco de la Contraofensiva aparece desdibujado de su experiencia militante en Nicaragua. Tan sólo Luciano de Gatica quedaría vinculado a este proceso, desarrollando tareas logísticas entre Nicaragua, México y Cuba, hasta que a finales de 1981 se asentó en Brasil con tareas partidarias. ${ }^{40}$

La implementación de la Contraofensiva generó dos disidencias en Montoneros. En mayo de 1979, rompería con la Conducción de esta organización un sector disconforme encabezado por Rodolfo Galimberti y Juan Gelman, que pasarían a desarrollar actividad política como Peronismo Montonero Auténtico (PMA) y, posteriormente, como Peronismo en la Resistencia. ${ }^{41}$ La segunda ruptura tendría lugar en abril de 1980, con la conformación en México de Montoneros 17 de Octubre (M-17). ${ }^{42}$ La fractura orgánica se había definido un mes antes, en una reunión sostenida en Managua entre los sectores disconformes y la Conducción Nacional de Montoneros. A la naciente organización se sumaría la jefa política de la Brigada Sanitaria, Sylvia Bermann, quien pasaría a integrarse al Consejo Provisorio de M-17. ${ }^{43}$

Aunque no se ha podido contrastar una vinculación orgánica efectiva con el agrupamiento encabezado por Galimberti, no deja de ser significativa la presencia de artículos firmados por otros dos miembros de la Brigada Sanitaria, José Carlos Escudero y Pedro Sarrasqueta, en la revista Revolución Peronista, editada en México por este colectivo disidente. ${ }^{44}$

Estos procesos de quiebres orgánicos, o alejamiento de la estructura política de origen, aparecen vinculados también al desarrollo de nuevas experiencias militantes, ligadas al desarrollo profesional en un contexto de cambio

39 Un caso paradigmático es el del abogado Héctor Amílcar Archetti, secuestrado en Mendoza en septiembre de 1980 cuando retornaba al país.

${ }^{40}$ Luciano de Gatica, entrevista citada.

${ }^{41}$ Mesa Promotora del PMA. Se constituye la Mesa Promotora del Peronismo Montonero Auténtico. 22 de mayo de 1979. Ref. A-21. Cedema, Valencia, España.

${ }^{42}$ Montoneros 17 de Octubre. A nuestros compañeros del pueblo argentino. Abril de 1980. Ref. A-21. Cedema, Valencia, España.

${ }^{43}$ Montoneros 17 de Octubre. Integrantes del Consejo provisorio. Abril de 1980. Ref. A-21. Cedema, Valencia, España.

44 “Escudero, J. C. Los militares y la salud en Argentina”, Revolución Peronista, s. n., ca. 1981, pp. 29-30; Sarrasqueta, P., "El fracaso económico oligárquico y la alternativa neodesarrollista”, Revolución Peronista, núm. 1, septiembre-octubre de 1981, pp. 14-15. Ref. A-9, CedemA, Valencia, España. 
social, que ofreció la reconstrucción de Nicaragua y la nueva institucionalidad revolucionaria.

En agosto de 1979, la Secretaría de Relaciones Exteriores del MPM impulsaría una tercera estructura de apoyo a Nicaragua, la Brigada de Reconstrucción "Compañero Rodolfo Walsh", bajo la consigna 'Devolver al pueblo lo que es del pueblo'. ${ }^{45}$ Esta tercera estructura nunca llegó a conformarse debido a la dispersión orgánica que experimentaba Montoneros, lo que, atendiendo al reclamo de la Brigada Sanitaria, ponía en entredicho la continuidad del trabajo realizado por este grupo: "No nos cabe la menor duda de que una parte significativa de lo realizado puede verse jaqueado por nuestra ausencia, cuando todavía no podíamos instrumentar o contribuir a ejecutar nuestro reemplazo. Una Brigada de reemplazo que previmos desde nuestra partida no sabemos por qué no llegó a dar continuidad a nuestra labor". ${ }^{46}$

Si bien la Brigada de Reconstrucción no tendría recorrido orgánico, el goteo de militantes montoneros que se incorporaron al proceso revolucionario nicaragüense no cesó. Estos internacionalistas se sumaron a las tareas de reconstrucción del país, integrándose como personal técnico en las instituciones revolucionarias, y participando de los diversos esfuerzos productivos y culturales impulsados por la revolución sandinista. En estos itinerarios militantes intervinieron redes organizativas partidarias, pero resultaron esenciales los contactos generados por las estructuras montoneras incorporadas durante la insurrección y en la etapa inmediatamente postinsurreccional. Es el caso de María Rosa Renzi y Elsa Soto. Renzi se incorporó al proceso sandinista en octubre de 1979, junto a su compañero. Su primera parada fue Diriamba: "Nosotros venimos a Nicaragua por un lado sensibilizados, pero también recibimos una carta de gente que había estado, posiblemente de Richard, ${ }^{47} \mathrm{y}$ con esa carta nos presentamos en Diriamba que fue donde ellos [la Brigada Sanitaria] estuvieron. Fernando Fernández, que era quien presidía la Junta de Gobierno de Diriamba nos dijo: 'ustedes no se van, ustedes se quedan conmigo.". ${ }^{48}$

${ }^{45}$ Vaca Narvaja, F., "Convocatoria a la Brigada de Reconstrucción 'Compañero Rodolfo Walsh”, Vencer, núms. 2/3, 1979, p. 38. Ref. A-9. CedemA, Valencia, España.

${ }^{46}$ Brigada Sanitaria "Adriana Haidar". Informe para el Consejo Superior del Movimiento Peronista Montonero sobre la actuación de la Brigada Sanitaria Adriana Haidar. Diciembre de 1979. Ref. Dig-APLg. Cedema, Valencia, España.

${ }^{47}$ Ricardo Holland, bioquímico de la Brigada Sanitaria Adriana Haidar.

${ }^{48}$ María Rosa Renzi, entrevista citada. 
Sus primeras funciones se orientaron a reconstruir la alcaldía y definir funciones en el gobierno municipal de Diriamba. De ahí, coincidiendo con un distanciamiento de su organización y la posterior ruptura de M-17, la pareja profundizaría su vinculación con el proceso sandinista: "Yo te diría que, poco a poco, los que fuimos de alguna manera M-17 nos fuimos mimetizando con el medio nica. De hecho, Marcela Cappi se mete al Consejo de Estado, Mario [su pareja] en el Ministerio de Vivienda, yo en Comercio Exterior. Todo el mundo de los que de alguna manera tuvimos la fractura." ${ }^{49}$

Elsa Soto adoptó un posicionamiento diferente con relación a la discusión dentro de Montoneros. Su pareja se había integrado al Grupo de Combate General San Martín y, en octubre de 1979, ella se sumó al proceso revolucionario como personal médico dentro del Ejército Popular Sandinista. Inicialmente, integrada a la Escuela Carlos Agüero, desde donde fue trasladada a una unidad militar en Matagalpa, hasta su regreso a la Argentina en noviembre de 1983. En su testimonio, Soto identifica la experiencia en Nicaragua como una forma de "prepararnos, obtener experiencia" para volver a la Argentina, y como la concreción de un "sueño" militante: "lo que no pudimos hacer nosotros acá, ellos lo pudieron hacer allá". ${ }^{50}$

En términos generales, los internacionalistas montoneros reconocen su experiencia en Nicaragua como una proyección de su militancia, sujeta a ciertas reconfiguraciones y a rupturas orgánicas. Así, en términos personales, la experiencia nicaragüense es afirmada en el imaginario como un momento de recuperación anímica y revitalización de su actividad militante, que rompió con las dinámicas del exilio. ${ }^{51}$ En segundo lugar, Nicaragua se vislumbra como una oportunidad de proyectar la militancia que había quedado trunca en el país de origen, convirtiéndose en parte protagónica en la construcción de una nueva sociedad revolucionaria. En esta línea, la integración al proceso sandinista es señalada como un momento de maduración política y culminación

49 María Rosa Renzi, entrevista citada.

50 Entrevista a Elsa Soto, realizada por Eudald Cortina Orero, el 11 de diciembre de 2015. Buenos Aires, Argentina.

${ }^{51}$ En este mismo sentido se expresa Sylvia Bermann en el informe final de la Brigada Sanitaria, donde reconoce en esta experiencia internacionalista una oportunidad para superar algunas situaciones generadas por el largo exilio. Al respecto, Bermann apunta a que la participación en el proceso nicaragüense se orientó "a despejar una atmósfera enrarecida" por lo que se describe como "patología del exilio". Así, la conformación de las diversas brigadas montoneras en Nicaragua se orientó en términos orgánicos a romper con la inercia de "supervivencia personal" del exilio y "revitalizar viejas experiencias militantes". 
de una vida militante, ligada a la posibilidad de generar cambios profundos a través de las instituciones (Cortina Orero, 2020).

En este sentido, podemos observar un proceso de tecnificación y profesionalización de las actividades solidarias que, sin abandonar un perfil político, se iría desligando del ámbito partidario, enlazándose con instituciones públicas y organismos no gubernamentales. En este contexto se enmarca la formación de un equipo de psiquiatras y psicólogos afincados en México que, a pedido del decano de la Facultad de Medicina de la Universidad Nacional Autónoma de Nicaragua (UNAN), sería impulsado por Sylvia Bermann en 1981. Este grupo, que posteriormente sería conocido como Equipo Internacionalista de Salud Mental México-Nicaragua (EISM-MN), estuvo integrado originalmente por Bermann, Marie Langer, Mario Campuzano, Beatriz Aguad, Leticia Cufré y Alicia Stolkiner. ${ }^{52}$

Bermann, Langer y Maldonado viajarían en octubre de 1981 a Nicaragua ${ }^{53}$ para "elaborar un diagnóstico" de las necesidades y definir los alcances de las tareas. El equipo se comprometía a viajar una semana al mes a Nicaragua para "favorecer la capacitación de profesionales y técnicos" locales, y desarrollar políticas de prevención y asistencia en el área de salud mental. ${ }^{54}$ Estas actividades se desarrollaron bajo el paraguas del Departamento de Atención a la Salud de la Universidad Autónoma Metropolitana, Unidad Xochimilco, mediante un acuerdo de coordinación con la UNAN. ${ }^{55}$ En estas tareas, el Equipo contaría con el apoyo económico de la oNG alemana Médico Internacional. ${ }^{56}$

El EISM-MN proseguiría su actividad sanitaria y docente en Nicaragua hasta principios de los 90, desarrollando proyectos como el de "Niño Acom-

${ }^{52}$ Bermann, S. Carta al Sr. Decano de la Facultad de Medicina, Dr. Fabio Salamanca. México, 14 de agosto de 1981. Fondo Equipo Internacionalista de Salud Mental México-Nicaragua. Archivo Histórico de la Universidad Nacional Autónoma de México (en adelante AHUnAm), México.

${ }^{53}$ Bermann, S. Carta al Dr. Fabio Salamanca. México, 17 de septiembre de 1981. Fondo Equipo Internacionalista de Salud Mental México-Nicaragua. Ahunam, México.

${ }_{54}$ Bermann, S. Carta al Sr. Decano de la Facultad de Medicina, Dr. Fabio Salamanca. México, 14 de agosto de 1981. Fondo Equipo Internacionalista de Salud Mental México-Nicaragua. AHUnam, México.

${ }_{55}$ Área de Salud Mental, Unidad Xochimilco, Universidad Autónoma Metropolitana. Programa de Coordinación con la Universidad Nacional de Nicaragua. México-Nicaragua, octubre de 1981. Fondo Equipo Internacionalista de Salud Mental México-Nicaragua. AHunAM, México.

${ }^{56}$ Equipo Internacionalista de Salud Mental México-Nicaragua. Nuestro Trabajo en Nicaragua. s. f. Fondo Equipo Internacionalista de Salud Mental México-Nicaragua. AHUnAM, México. 
pañado" en el Hospital Escuela de León, el Centro de Atención Psicosocial (CAPs) de León, la Unidad de Terapia Intensiva del Hospital Psiquiátrico de Managua y la implementación del plan de salud mental en la Regional III de Salud (Managua). ${ }^{57}$

\section{CONCLUSIONES}

A lo largo de este artículo, hemos rastreado la movilización transnacional de la organización Montoneros que, con antecedentes durante la etapa de gobiernos peronistas -como la gira internacional de la JP a Panamá, México, Cuba y Perú en 1974-, se acentuó como resultado de la salida al exilio de sus militantes ante la actividad de la Triple A y la instauración de la dictadura militar en Argentina. Durante este periodo, Montoneros consolidó sus vínculos internacionales, estrechando sus relaciones institucionales, entre las redes de exiliados en el ámbito de la solidaridad, y alcanzando acuerdos de colaboración con organizaciones revolucionarias como el FSLN.

Fruto de este acuerdo, Montoneros puso al servicio de la organización nicaragüense la emisora de onda corta, con sede en Costa Rica, Radio Noticias del Continente ( $\mathrm{RNC}$ ), y organizó dos contingentes internacionalistas para apoyar los esfuerzos insurreccionales del fSLN: el Grupo de Combate General San Martín y la Brigada Sanitaria Adriana Haidar, caso en el que hemos profundizado en este trabajo.

La Brigada Sanitaria fue conformada en México por la Rama de Intelectuales y Profesionales del Movimiento Peronista Montonero, con un perfil eminentemente técnico y orientada, en sus inicios, a realizar "sanidad de guerra" en el contexto insurreccional que atravesaba Nicaragua. Su organización es muestra del complejo entramado de redes transnacionales desarrollado por Montoneros en el exilio, contando con apoyo formativo cubano en medicina de guerra y gozando del aval de la Secretaría de Gobernación de México para la movilización de sus integrantes y los insumos médicos.

El rápido desenlace del proceso insurreccional sandinista obligó a replantear los objetivos de la Brigada, que se asentó en el municipio de Diriam-

${ }^{57}$ Equipo Internacionalista de Salud Mental México-Nicaragua. Nuestro Trabajo en Nicaragua, s. f. Fondo Equipo Internacionalista de Salud Mental México-Nicaragua. AHunam, México. 
ba (Carazo). En un contexto de reconstrucción, los esfuerzos se orientaron hacia la puesta en funcionamiento de estructuras asistenciales básicas, como el Hospital San José de Diriamba, la implementación de un plan de salud centrado en la acción preventiva y la educación en salud de la población, además de la formación y especialización de personal local.

Atendiendo a las características del contingente, se implementaron acciones específicas en atención pediátrica, odontológica y psiquiátrica, campos en los que especialistas del grupo asesoraron a las emergentes instituciones revolucionarias, como el Ministerio de Salud y el Instituto Nicaragüense de Reforma Agraria. Este trabajo inicial de la Brigada, acotado en el tiempo entre junio y octubre de 1979, facilitó la incorporación de nuevos militantes montoneros que aportaron al proceso sandinista desde su actividad profesional.

La experiencia internacionalista de Montoneros en Nicaragua fue atravesada por el proceso de dispersión orgánica y crisis interna que esta organización experimentaba como resultado del lanzamiento de la Contraofensiva Estratégica. La Brigada Sanitaria no escapó a estas tensiones y, tras el cierre de la experiencia internacionalista, la jefa política del contingente, Sylvia Bermann, se incorporó a la disidencia de Montoneros 17 de Octubre (M-17).

Observamos que este proceso de disgregación y distanciamiento con la estructura política de origen aparece ligado a la existencia de una propuesta militante alternativa como la Revolución Sandinista, que permitió a estos militantes insertarse en la nueva institucionalidad revolucionaria y desarrollarse profesionalmente en un contexto de transformación social. En este sentido, asistimos, por un lado, a la proyección de militancias sujetas a reconfiguraciones identitarias y quiebres orgánicos. Y, por otro lado, a un proceso de tecnificación de la actividad solidaria que, sin perder el perfil político, se orientó a la asistencia técnica a Nicaragua de la mano de instituciones públicas y ong.

Estas evidencias nos permiten señalar posibles líneas de investigación que profundicen tanto en la naturaleza e impacto de las redes militantes transnacionales como en la transformación de conceptos como internacionalismo y solidaridad. En relación con el primer aspecto, consideramos esencial indagar en la compleja articulación de redes que combinaron relaciones de carácter conspirativo y clandestino con vínculos institucionales y de naturaleza profesional. Del mismo modo, se hace necesario profundizar en cómo estas experiencias transnacionales incidieron en los procesos de transformación identitaria y en la proyección político-organizativa de los propios militantes. En este sentido, identificamos como un segundo reto ahondar en la transfor- 
mación que experimentó a lo largo de la década de los ochenta el ámbito de la solidaridad, desde un movimiento alineado políticamente a las organizaciones revolucionarias que iría transformando su actividad, paulatinamente, hacia la asistencia técnica especializada y hacia el ámbito de la cooperación internacional.

\section{LISTA DE REFERENCIAS}

Confino, H. E. (2018). La contraofensiva estratégica de Montoneros. Entre el exilio y la militancia revolucionaria (1976-1980) [Tesis de doctorado inédita]. Universidad Nacional de San Martín, Argentina.

Cortina Orero, E. (2017). Internacionalismo y revolución sandinista: proyecciones militantes y reformulaciones orgánicas en la izquierda revolucionaria argentina. Estudios Interdisciplinarios de América Latina y el Caribe, 28(2), 80-103. Recuperado de http://eial.tau.ac.il/index.php/eial/article/view/1521

Cortina Orero, E. (2020). Militancia transnacional de Montoneros en Centroamérica. De la solidaridad antiimperialista a la lucha por la recuperación democrática. En K. Pirker y J. Rostica (eds.), Confrontación de imaginarios: antiimperialismo, democracia y modernización (en prensa). Ciudad de México: Instituto Mora/Clacso [en prensa].

Cuestas, R. (2005). La dictadura militar argentina y el genocidio centroamericano. Córdoba: SIMA.

Escudero, J. (1980a). Starting from year one: The politics of health in Nicaragua. International Journal of Health Services, 10(4), 647-656. DoI: https://doi.org/10.2190/ NT2B-0K80-EK76-26MV

Escudero, J. (1980b). Año cero en salud. Cuadernos de Marcha, 1(5), 47-53.

Escudero, J. (1981). Health care in the new Nicaragua. Nueva York: Medical Aid for Nicaragua.

García Fernández, A. (2018). Rompiendo el cerco. La experiencia de Radio Noticias del Continente en Costa Rica (1979-1981). Diálogos. Revista Electrónica de Historia, 19(2), 36-57. DoI: https://doi.org/10.15517/dre.v19i2.31160

Harmer, T. y Martín Álvarez, A. (2017). Revolutionary transnationalism in historical perspective: Militant networks in the Americas in the second half of the twentieth century. Estudios Interdisciplinarios de América Latina y el Caribe, 28(2), 7-13. Recuperado de http://eial.tau.ac.il/index.php/eial/issue/view/108 
Marchesi, A. (2019). Hacer la revolución. Guerrillas latinoamericanas, de los años sesenta a la caída del Muro. Buenos Aires: Siglo XXI Editores.

Martín Álvarez, A. y Rey Tristán, E. (2012). La oleada revolucionaria latinoamericana contemporánea, 1959-1996. Definición, caracterización y algunas claves para su análisis. Naveg@mérica. Revista Electrónica Editada por la Asociación Española de Americanistas, 9. Recuperado de https://revistas.um.es/navegamerica/article/ view/161591

Martín Álvarez, A. y Rey Tristán, E. (2017). Introduction. En A. Martín Álvarez y E. Rey Tristán (eds.), Revolutionary violence and the new left: Transnational perspectives (pp. 1-23). Nueva York, NY-Abingdon, Oxon: Routledge.

Martín Álvarez, A. y Rey Tristán, E. (2018). La dimensión transnacional de la izquierda armada. América Latina Hoy, 80, 9-28. DoI: https://doi.org/10.14201/ alh201880928

Rapoport, D. C. (2004). Modern terror: The four waves. En A. Cronin, Audrey y J. M. Ludes (eds.), Attacking terrorism: Elements of a grand strategy (pp. 46-73). Washington, D.C.: Georgetown University Press.

Rapoport, D. C. (2017). Reflections on the third or new left wave. En A. Martín Álvarez y E. Rey Tristán (eds.), Revolutionary violence and the new left: Transnational perspectives (pp. 24-64). Nueva York, NY; Abingdon, Oxon: Routledge.

Rey Tristán, E. (2014). Las luchas revolucionarias en América Latina en perspectiva regional. En V. Oikión Solano, M. López Ávalos y E. Rey Tristán (eds.), El estudio de las luchas revolucionarias en América Latina (1959-1996). Estado de la cuestión (pp. 87-109). Zamora de Michoacán: El Colegio de Michoacán/Santiago de Compostela: Servizo de Publicacións e Intercambio Científico.

Ríos, J., y Azcona, M. (2019). Historia de las guerrillas en América Latina. Madrid: Los Libros de la Catarata.

Rodríguez Esperón, C. (2018). Comunicación y lucha armada. Tres propuestas de articulación a partir de la experiencia de Radio Noticias del Continente. Izquierdas (Santiago), 41, 44-58. DoI: http://dx.doi.org/10.4067/S0718-50492018000400044

Rojas Mira, C. F. (2014). Exilios sudamericanos en México: los casos argentino y chileno. Pacarina del Sur, 19. Recuperado de http://pacarinadelsur.com/home/ abordajes-y-contiendas/937-exilios-sudamericanos-en-mexico-los-casos-argentino-y-chileno

Roniger, L. (2012). Destierro en América Latina: Un campo de estudio transnacional e histórico en expansión. Pacarina del Sur. Recuperado de http://pacarinadelsur.com/home/abordajes-y-contiendas/318-destierro-y-exilio-en-america-latina-un-campo-de-estudio-transnacional-e-historico-en-expansion 
Vaca Narvaja, G; Frugoni, F. (2002). Fernando Vaca Narvaja, con igual ánimo. Buenos Aires: Colihue.

Yankelevich, P. (2010). Ráfagas de un exilio. Argentinos en México, 1974-1983. México: El Colegio de México.

Yankelevich, P. (2016). Los exilios en el pasado reciente sudamericano. Migraciones y Exilios, 16, 11-31.

\section{OTRAS FUENTES}

Archivos

Ahunam Archivo Histórico de la Universidad Nacional Autónoma de México, México.

Cedema Centro de Documentación de los Movimientos Armados, Valencia, España. 